\title{
El valor de la indicación farmacéutica
}

\author{
Luis Salar Ibáñez
}

Doctor en Farmacia. Farmacéutico comunitario en Valencia.

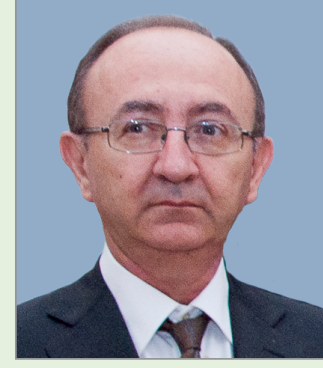

Luis Salar lbáñez
"Qué me da para", síntomas menores, indicación farmacéutica... Son distintas formas de referirse a lo mismo, a una actividad que se viene realizando en las farmacias desde que el mundo es mundo. Según el Consenso sobre Atención Farmacéutica y, posteriormente, Foro de Atención Farmacéutica, es la actividad por la cual un paciente nos demanda una solución a un problema de salud (1-3). Esto se plantea en las farmacias, pero también en los herbolarios, las parafarmacias, las perfumerías, las tiendas de alimentos especiales... y a un amigo, el vecino, el compañero de trabajo... Obviamente las expectativas del paciente y la calidad de la solución aportada no son las mismas en la farmacia o en el resto de establecimientos. En la farmacia hay un profesional sanitario, universitario, que trabaja con unos procedimientos consensuados y con base científica.

Hace años estaba yo dándole vueltas a los criterios de derivación al médico en ojo seco cuando llegó a la farmacia una amiga de juventud, ahora oftalmóloga. Le pedí ayuda para determinar esos criterios y se me quedó mirando fijamente. ¿Eso no es intrusismo? me dijo. Tuve que explicarle que no, que no es intrusismo, que es una actividad perfectamente legal si se hace dentro de unas limitaciones, y que eran precisamente esas limitaciones las que quería que me ayudara a establecer. Además, es una demanda social. A mí me preguntan todos los días por cosas parecidas, puedo hacerlo bien o mal, pero tengo que hacerlo. Lo entendió perfectamente y me ayudó a definir los criterios de derivación al médico. Sin saberlo ella y yo estábamos haciendo algo muy necesario, llegar a unos criterios consensuados entre las dos profesiones.

Esta actividad es muy frecuente. En todas las farmacias nos lo demandan varias veces al día, lo cual hace que en toda España sean centenares de miles al día, millones a la semana. ¿Qué pasaría si esto no se hiciera? Pues unos cuantos pacientes se quedarían en su casa, otros irían al médico a consultar, y, lamentablemente, otros caerian en manos de charlatanes. Es obvio que el servicio de indicación farmacéutica contribuye a mejorar la salud de la población en unos procesos que son poco importantes pero que afectan mucho a la calidad de vida de las personas. Y también es obvio que evita muchas consultas al médico. Es difícil calcular cuántas consultas evita porque nos adentramos en el terreno de las hipótesis. ¿Qué hubiera hecho Don José si no le hubiéramos indicado esas gotas para su congestión nasal? Es difícil de saber, pero es evidente que algunos "Don Josés" acudirían al médico, congestionando las consultas con su nariz congestionada.

Está claro que la indicación farmacéutica es un servicio que mejora la salud de la población y disminuye la presión en las consultas médicas (4), para ello debemos hacerlo bien. De otra forma corremos el riesgo de ser nosotros mismos imprecisos. Eso implica una formación específica. Es incomprensible que en ninguna de las facultades de Farmacia de España se imparta una asignatura que explique la patología necesaria para establecer y entender los criterios de derivación al médico. No pretendo que me expliquen cómo tratar a un paciente ya que para ello es necesario tener pacientes y, salvo honrosísimas excepciones, en las facultades de Farmacia los únicos "pacientes" son los alumnos. Pero lo que pone en los libros, la patología, sí que me lo deben explicar en la facultad.

Además, son pocos los medicamentos disponibles para la indicación farmacéutica. ¿Tenemos que estar tan limitados? Probablemente podamos ampliar nuestro campo de actuación. Por ejemplo, en un magnífico artículo (5), ya algo antiguo, se propone que algunos antibióticos en algunos casos concretos puedan ser dispensados sin receta. Y habrá otros problemas de salud en casos concretos en los que podamos intervenir con seguridad aliviando, de esta forma, a los pacientes y a las consultas de los centros de salud.

SEFAC tiene en este momento en fase de elaboración el programa I-VALOR. Con este programa se pretende fomentar la indicación farmacéutica protocolizada y documentada, y proporcionar herramientas que faciliten al farmacéutico la toma de decisiones, el registro de la actividad y la emisión de informes de derivación al médico. I-VALOR cuenta con 
importantes apoyos institucionales como los del Consejo General de Colegios Oficiales de Farmacéuticos, la Fundación Pharmaceutical Care, el Grupo de Investigación en Atención Farmacéutica de la Universidad de Granada y la Asociación para el Autocuidado de la Salud (Anefp), y espera contar próximamente con la complicidad de los colegios de farmacéuticos de toda España, que ya apoyaron el exitoso programa precedente $D-V A L O R$, centrado en la dispensación. Está previsto que empiece en noviembre-diciembre de este año y puede ser un paso importante para mejorar y consolidar esta actividad en la rutina profesional del farmacéutico comunitario.

\section{Referencias bibliográficas}

1. Panel de Consenso. Consenso sobre Atención Farmacéutica. Madrid: Ministerio de Sanidad y Consumo; 2001.
2. Grupo de Expertos. Foro de Atención Farmacéutica. Panel de Consenso. Madrid: Consejo General de Colegios Oficiales de Farmacéuticos; 2008.

3. Grupo de Expertos. Foro de Atención Farmacéutica en Farmacia Comunitaria. Guía práctica para los Servicios de Atención Farmacéutica en la Farmacia Comunitaria. Madrid: Consejo General de Colegios Oficiales de Farmacéuticos; 2010.

4. Machuca M, Oñate B, Machuca MP, Gastelurrutia P, Gutiérrez-Aranda L, López-Fernández E, et al. La indicación farmacéutica disminuye las visitas al médico y resuelve las demandas de los pacientes. Seguim Farmacoter 2003;1(3): 110-114.

5. Reeves D, Finch R, Bax R, Davey P, Li Wan Po A, Lingam G, et al. Self-medication of antibacterials without prescription (also called "over-the-counter" use). A report of a Working Party of the British Society for Antimicrobial Chemotherapy. Journal of Antimicrobial Chemotherapy. 1999;44:163-177. doi:10.1093/jac/44.2.163 